\title{
Lexicalization of Light Verb Structures and the Semantics of Nouns*
}

\author{
M. Teresa Espinal
}

Universitat Autònoma de Barcelona. Departament de Filologia Catalana

08193 Bellaterra (Barcelona). Spain

Teresa.Espinal@uab.es

\begin{abstract}
In this study I shall focus on two Romance idiomatic patterns and the semantics of nouns. It is shown that idioms, in addition to having distinct basic argument structure representations, are formed in syntax by various instantiations of Merge. It is argued that there is a lexicalization pattern reflecting semantic conflation (Talmy 1985, 2000) between cause and degree. This pattern, in syntactic terms, is the output of subsequent Merge operations (Chomsky 1995) between the object noun of a monadic argument structure, an indefinite quantifier and an adjunct phrase. The study of this lexicalization pattern is of interest with regard to the semantics of bare nouns, especially of bare count singular nouns in object position; it is proved that bare nouns are interpreted as properties, and, because of this, they permit quantification over degrees. By contrast, there is a second lexicalization pattern starting from a composite argument structure which licenses an individual or a kind denoting reading for the DP object.
\end{abstract}

Key words: syntax, semantics, idioms, lexicalization patterns, bare nouns.

\section{Table of Contents}

\section{Introduction}

2. Description of the data

3. Argument structures

4. The syntax of lexicalized light-verb structures
5. The semantics of lexicalized light-verb structures

6. Concluding remarks

\section{References}

* Financial support for the development of this project has been obtained from the Catalan Direcció General de Recerca (2001SGR/000150, and the Centre de Referència en Enginyeria Lingüística), and from the Spanish Ministerio de Educación, Cultura y Deportes (BFF-2000-0403-C02-01).

I have benefitted from discussion with J.M. Brucart, O. Fernández, S. Iatridou, A. Ojeda, C. Picallo, and G. Rigau. Special acknowledgements should also be given to J. Mateu and L.McNally, who made insightful comments on previous versions of the paper. L. Brugè and A.M. Martins provided me with relevant Italian and Portuguese examples. O. Fox improved the English glosses.

Previous versions of this paper have been distributed as a research report (GGT-02-08) of the Grup de Gramàtica Teòrica de la Universitat Autònoma de Barcelona (http://seneca.uab.es/ ggt/reports.htm), and as a working paper in Cuadernos de Lingüística del I.U. Ortega y Gasset, 2003, X, 94-124. 


\section{Introduction}

In the late sixties standard generative grammarians started arguing against transformational analyses within the lexicon, introducing a strict separation between syntax and semantics, and supporting a view according to which syntax was considered the core of grammar and semantics an interpretative component. According to this view, idiomatic expressions, if interesting at all, are banished out of grammar, particularly out of syntax proper. Some linguists claim that the lexicon embraces items larger than words under lexical categories such as N, V, and so on (Chomsky 1981). Others, in order to account for the fact that the meaning of idioms cannot be predicted from the meaning of their parts, put forward the hypothesis that idioms require specific syntactic - conceptual correspondence rules (Jackendoff 1997). Cognitive linguists postulate some metaphorical and metonymic mappings into figurative patterns of human understanding (Gibbs 1995).

Reacting against the tradition that assumes that idiomatic constructions involve non-compositional meanings, I agree with those linguists who claim that most of the idioms are compositional (Nunberg - Sag - Wasow 1994, Marantz 1996, McGinnis 2002, Mateu - Espinal forthcoming, among others). ${ }^{1}$

The main purpose of this paper is to study the correlation between different syntactic argument structures and the semantics of NPs by comparing two distinct idiomatic or lexicalization patterns that exist in Romance languages. Syntactically, it will be argued that one of these patterns (e.g. fer un sol de justicia 'it's scorching hot', lit.: make a sun of justice) is the output of subsequent Merge operations (Chomsky 1995) between the object bare noun of a monadic argument structure, a head Noun which denotes some property that permits grading (e.g. fer sol 'it's sunny', lit.: make sun), the indefinite specifier un 'a', and a non-predicative relative-like adjunct. The second pattern (e.g. tenir el cap a la boja 'to be round the bend', lit.: have the head at the madness) will be assigned a composite argument structure, which involves an object NP followed by a predicative adjective-like complement.

Semantically, it will be shown that the study of lexicalized light verb expressions provides additional arguments to support the hypothesis that object count nouns of VP idioms, under certain syntactic conditions, must be interpreted as property denoting expressions at the syntax-semantics interface (Laca 1996, McNally 1995, Espinal 2001). Thus, I shall put forward the hypothesis that determinerless nouns occurring in object position of analytic verbal expressions do not activate a type-shifting operation from properties to either referential entities or generalized quantifiers over individuals (Carlson 1999, Chierchia 1998, Longobardi 2001, Partee 1987). Furthermore, it will be shown that dyadic idiomatic structures license an interpretation of the object DP as either an individual or a kind denoting expression. The main claim put forward in this paper is that lexicalized light verb structures, with different argument structures at the compu-

1. See also Everaert et al. (1995), Mendívil (1999), and O'Grady (1998) for relevant references on the study of idioms. 
tational system, license different noun interpretations at the syntax-semantics interface.

The structure of the paper is as follows. In Section 2 two different paradigms of lexicalized light verb structures are introduced and described. In Section 3 it is argued that the two paradigms of idioms under analysis have different argument structures: one being basically monadic, and the other dyadic. I am going to assume that, in (lexical-)syntax, idiomatic structures are identified by both an argument structure (Hale - Keyser 1993, 2002) and a continuity constraint (O'Grady 1998), whereas light verb structures are only associated with an argument structure. In Section 4 I shall mainly focus on the syntax of the lexicalization patterns under study. $^{2}$ It is claimed that one pattern results from the output of a syntactic Merge process induced by the defective semantic features of the nominal object head of a monadic argument structure, since a bare count noun is not expected in object position in Romance; the second pattern is characterized by a transitive argument structure which combines an unergative argument structure with a spatial relational head (Mateu 2002). Finally, Section 5 focuses on the semantics of monadic argument structures, and describes the most relevant aspects regarding the semantics of bare count nouns in object position of idiomatic constructions. I shall argue that the semantics of Noun objects correlates with the argument structure representations which different light verb structures are associated with. Section 5 is also devoted to an account of the syntactic and semantic behavior of $\mathrm{D}$ (eterminer) un in both paradigms: one being an existential quantifier over degrees, and the other being an existential quantifier over individual entities.

\section{Description of the data}

Let us first consider the main features of two distinct lexicalization patterns, exemplified by the two paradigms of data listed in (1) and (2) (which from now on will be referred to as class 1 and class 2 idioms, respectively). The examples given, followed by the literal translation and the English gloss, are taken from Catalan, although similar data may be found across Romance languages. ${ }^{3}$

2. I'll use the term 'lexicalization pattern' to refer to two quite productive idiomatic patterns by means of which light verb structures become lexicalized in Romance languages. This use of the term should not be confused with the one put forward by Talmy $(1985,2000)$.

3. Examples of class 1 and class 2 idioms have been obtained from a corpus of over 15.500 Catalan idioms. See Espinal (2004).

Of special interest to the topic presented here is the fact that similar examples to those given in class 1 are found in other Romance languages, but not in Germanic languages; for example, avoir une faim de loup in French; hacer un frío de padre y muy señor mío, tener un sueño de miedo, tener un morro que se lo pisa in Spanish; ter uma fome de cão, estar um calor de assar passarinhos in Portuguese; and avere una lingua que taglia e cuce, avere un cervello da gallina, fare un fredo cane, fare un freddo boia, averelessere una giornata da cani in Italian; among others. Therefore, the study of this lexicalization pattern seems to reveal a parametrization of idiomatic patterns in accordance with the well-known typological distinction between Romance and Germanic languages. 
(1) a. fer un aire que talla. make an air that cuts

'There's a cutting wind'.

b. fer un fred de mil dimonis. make a cold of one-thousand devils 'It's freezing cold'.

c. fer un sol de justícia. make a sun of justice

'It's scorching hot'.

d. tenir una son que no s'hi veu. have a sleep that not CL sees

'To feel drowsy'.

e. tenir una gana que l'aixeca. have a hunger that CL raises

'To have a voracious appetite'.

f. tenir un morro que se'l trepitja. have a snout that CL walks-on

'To have a brass neck'.

(2) a. fer la vida impossible (a algú). make the life impossible (to somebody)

'To make life impossible (for someone)'.

b. fer el cor fort.

make the heart strong

'To summon up courage'.

c. fer els ulls grossos. make the eyes big

'To turn a blind eye'.

d. tenir la consciència bruta. have the conscience dirty

'To have a guilty conscience'.

e. tenir el cap a la boja. have the head at the madness

'To be round the bend'.

f. tenir el / un geni fort. have the / a genious tough

'To have a strong character'.

g. posar el / un cap com un tabal. put the / a head as a drum

'To drive someone mad'.

Apparently, what is common among the data in (1) and (2) is a V + object structure, with a light verb as the verbal head (either fer 'make', or a heavier light predicate such as posar 'put' - see Bosque 2001—, which can be said to denote a dynamic cause, or tenir 'have', which can be said to denote a static cause - Mateu 2000, Mateu - Amadas 2001-), followed by a nominal and a second constituent. ${ }^{4}$ However, there are some significant differences between (1) and (2), as shown by 
the fact that these two classes of idiomatic structures are associated with different semantic instructions and with different determiner and pronominal strategies.

The idiomatic pattern in (1) involves the concepts of cause and degree. In accordance with this claim, the pattern in (1), but not that in (2), relates to a light verb schema in which a light verb expressing an internal cause (Levin - Rappaport-Hovav 1995 ) is followed by a bare noun (either a mass - e.g. aire, fred, son, gana-, or a count noun - e.g. sol, morro-). Notice, furthermore, that the head $\mathrm{N}$ is always interpreted similar to a mass / continuous noun (i.e. a continuously divisible entity, in Ojeda's 1984 terms, or an inner mass predicate, following Bosque - Masullo's 1998 terms). It corresponds to an unbounded and a potentially gradable property, and therefore it can be modified by a YP that restricts the interpretation of the noun to a high degree. The basic light verb expressions underlying the paradigm in (1) are given in (3).

(3) a. Fer aire.

make air

'It's windy'.

b. Fer fred.

make cold

'It's cold'.

c. Fer sol.

make sun

'It's sunny'.

d. Tenir son. have sleep

'To be sleepy'.

e. Tenir gana. have hunger

'To be hungry'.

f. Tenir morro. have snout

'To be cheeky'.

Let me now consider the above mentioned determiner and pronominal strategies. First, notice that in (2) the $\mathrm{D}$ (eterminer) which precedes the object $\mathrm{N}$ (oun) is not completely fixed, as shown by the frequent $e l$ 'the' / un 'a' alternation. This syntactic variation should be related to the fact that the object noun of class 2 idioms can either be individuated by means of a definite $\mathrm{D}$, or quantified by means of an existential quantifier. Correspondingly, (4a) can be paraphrased as in (4b).

a. tenir el / un cervell de gat. have the / a brain of cat

b. tenir el / un cervell propi d'un gat. have the / a brain characteristic of a cat
Class 2

'To be pea-brained'

It is interesting to point out that a $\mathrm{D}$ alternation vanishes when we consider class 1 idioms, as shown in (5). 


\section{(5) Catalan}

a. fer un / *el sol de justícia. make a / the sun of justice

Class 1

'It's scorching hot'.

\section{Italian}

b. avere una / *la lingua que taglia e cuce. have a / the tongue that cuts and sews

'To have a foul mouth'.

In addition, notice that those light $\mathrm{V}+$ bare $\mathrm{N}$ expressions that class 1 idioms are associated with (see the data in (3)) allow prenominal degree quantifiers and modifiers, as shown in (6) and (7), thus suggesting that their object nouns have a semantic interpretation which is different from that corresponding to object nouns in (4).

a. fer sol. make sun

b. fer més / un bon sol. make more / a good sun

(7) a. tenir llengua.

have tongue

b. tenir molta / bona llengua. have much / good tongue
$(=3 \mathrm{c})$

'It's sunny'.

'It's sunnier / It's brilliant sunshine'.

'To make a sharp reply / To have an eloquent tongue'.

Second, in (2) both the object and the second complement can be pronominalized simultaneously, although this is not intended to mean that either the DP or the YP have any particular reference (Nunberg - Sag - Wasow 1994, Simatos 1997, Espinal 2001). By contrast, class 1 idioms only allow pronominalization of the bare object noun. Consider the data in (8) and (9).

a. fer la vida impossible (a algú).

Class 2 make the life impossible (to somebody)

'To make life impossible (for someone)'

b. Els $\underline{k}_{\underline{a}_{i}} \underline{h i}_{j}$ fan tant com poden, $\underline{\text { la vida }}_{\mathrm{i}} \underline{\text { impossible }}_{\mathrm{j}}$ als seus pares ${ }_{\mathrm{k}}$. CL make as much as can, the life impossible to their parents 'As much as they can, they make life impossible for their parents'.

a. fer un aire que talla.

Class 1 make an air that cuts

'It's a cutting wind'

b. -Ara fa un aire que talla al carrer. -Quan he vingut també en feia now makes an air that cuts at the street when have come also CL make (aire / \# aire que talla / \# un aire que talla) air / air that cuts / an air that cuts)

'-Now there's a cutting wind. -It was also windly when I came'. 
In purely syntactic terms, the pronominalization strategy of class 2 idioms should be associated with its having a minor clause structure, with an AP or a PP predicating of a nominal subject (Stowell 1983). That is, from a structural perspective, this final constituent has a relational status. From a cognitive perspective, in class 2 idioms the YP constituent is to be interpreted as a conceptual predicate which stands on an abstract Ground relationship with regard to an object Figure NP. ${ }^{5}$ Accordingly, example (10a) must be interpreted as in (10b).

\section{a. fer el cor fort.} make the heart strong make the heart at a strong state
Class 2

'To summon up courage'.

By contrast, in class 1 idioms there is no predication, but a degree modification of a bare N. From a structural perspective, the final constituent is an adjunct of a nominal clause. Therefore, the YP constituent can never be interpreted as an abstract Ground, but only as a satellite phrase, and the object NP cannot be interpreted as a concrete Figure.

To sum up, the set of properties just pointed out suggest that class 1 and class 2 idiomatic constructions are structurally distinct, in spite of their apparent superficial similarities. ${ }^{6}$

Also relevant to the discussion that follows is the observation that the nominal expressions we find in class 1 idioms also occur in isolation, without a light verb. This is illustrated in the Spanish examples given in (11), which have been taken from the Reference Corpus of Contemporary Spanish of the Real Academia Española.

(11) a. En las afueras del pueblo, con un frío que pelaba, porque el invierno on the outside of the village, with a cold that cut, because the winter ya estaba.

already was

'On the outside of the village, with a freezing cold, because winter was already there'

b. La mañana era muy calurosa; Madrid languidecía bajo un sol de justicia. the morning was very hot; Madrid languished under a sun of justice 'On that morning it was very hot; Madrid was languishing in the blazing sunshine'.

5. These terms, although taken from Gestalt psychology, are interpreted by Talmy $(1985,2000)$ as follows: «the Figure is a moving or conceptually movable object whose path or site is at issue; the Ground is a reference-frame, or a reference-point stationary within a reference-frame, with respect to which the Figure's path or site is characterized» (1985:61).

6. For the purposes of this paper, which describes the correlation between argument structures and object noun interpretations, syntactic differences attributed to the fact that some idioms have expletive subjects, while others have null objects within the relative clause, and still others have an object pronoun which must corefer with the subject of the light verb are not relevant. 
c. A mi izquierda el campeón, el niño de la feria, setenta y un kilos, dos to my left the champion, the boy of the fair, seventy one kilos, two piernas, dos brazos y un morro que se lo pisa, González. legs, two arms and a snout that CL walk-on, González 'To my left the champion, González, the boy of the fair, seventy one kilos, two legs, two arms and a brass neck'.

It should also be noticed that, although both class 1 idioms and the nominal expressions in (11) denote high degree, they can never co-occur with an explicit degree expression.

(12) a. *Fa massa / molt / més / força sol de justícia.

(Catalan) makes too much / much / more / quite sun of justice

b. ${ }^{*}$ Cuanto / demasiado / más / bastante morro que se lo pisa. (Spanish) how much / too much / more / quite snout that $\mathrm{Cl}$ walks-on

This suggests the hypothesis that the syntactic category underlying the nominal expressions in (1) and (11) is a N, not a Deg (which has been postulated for explicit degree expressions, see Corver 1991). With this in mind, the additional PP I that-P constituent (e.g. Spanish que pelaba lit.: that cut, de justicia lit.: of justice, que se lo pisa lit.: that walks on, in (11)), or even an additional nominal constituent (e.g. cane 'dog', boia 'hangman' in Italian idioms fare un freddo cane lit.: make a cold dog, fare un freddo boia lit.: make a cold hangman), must be conceived as a modifier; that is, as an adjunct of a bare gradable noun. ${ }^{7}$ Thus, evaluative bare nouns behave like evaluative bare adjectives in that they license satellite constituents (Neeleman - van de Koot - Doetjes 2003). From this, it follows that the concept of degree associated with these data must be related to the semantic properties of the Noun itself, not to a hypothetical Deg constituent.

I shall come back to this question in Section 5. Meanwhile, the aim of the following section is to show that an appropriate account of the lexicalized patterns in class 1 and class 2 idioms is provided if, and only if, light verb expressions are associated with appropriate argument structures. The main claim I shall put forward is that only monadic structures with a bare noun object can be lexicalized following the paradigm in (1). An analysis based on two distinct argument structures is the clue to understanding the syntactic and semantic properties of the two idiomatic patterns under consideration.

7. Some modifiers are free to combine with any mass (e.g. hambre 'hunger') or count noun (e.g. coche 'car'), but are always associated with an interpretation of high degree.

(i) a. Tengo un hambre de miedo / de muerte have a hunger of fear / of death 'I'm terribly hungry'

b. Se ha comprado un coche de la hostia / que te cagas

CL has bought a car of the bash / that you shit 'She has bought an incredible car' 


\section{Argument structures}

It has been assumed in the linguistic literature that light verbs lack a thematic argument structure. Therefore, in light verb constructions $\theta$-marking has been conceived as a process of complex predicate formation by argument transfer (Grimshaw - Mester 1988). It has also been assumed that object Nouns display a specific thematic grid that must be saturated by $\theta$-binding (Higginbotham 1985:559-568). An additional assumption has been that, in the absence of a definite determiner, a light verb allows that the argument structure of the noun be projected upwards by means of a syntactic process of reanalysis (Mendívil 1999: 80).

In these classical terms, different nouns might be said to have different thematic grids as part of their lexical entries and, therefore, seem to require different licensing mechanisms. Thus, following a thematic approach, the answer to the question of what licenses determinerless common nouns in complement object position is highly dependent on the type of noun in question. When the object noun has an argument structure with an eventive argument (in davidsonian terms), this property is to be saturated by syntactic reanalysis which projects the $\langle\mathrm{e}\rangle$ nominal requirement to the $\mathrm{V}$ category containing a light verb with specific aspectual features. ${ }^{8}$ However, when the object noun is a bare count noun which combines with a light verb, then the object count noun should be licensed by a process of thematic reduction, since there is no determiner in [Spec, NP] responsible for its $\theta$-binding. ${ }^{9}$

In other words, the main objection to a classical thematic analysis of the paradigms in (3), is that this approach can only provide an adequate account of the data by postulating different licensing mechanisms for the various subsets of light verb expressions identified. Depending on the thematic grid of the noun, the relevant operations required for its interpretation seem to differ: $\theta$-binding, syntactic reanalysis, and thematic reduction. However, none of these operations can provide a unified account of the lexicalization pattern illustrated in (1), nor can they account for the fact that this idiomatic pattern is exclusively superimposed on a monadic argument structure, never on a composite argument structure.

Let me now consider the basic elements of the argument structures underlying class 1 and class 2 idioms. I repeat (1c) and (2e) for convenience:
a. fer un sol de justícia.
'It's scorching hot'
Class 1
b. tenir el cap a la boja.
'To be round the bend'
Class 2

My hypothesis is that (13a) starts from a basic monadic argument structure (like analytic unergatives), whereas (13b) has a composite dyadic argument con-

8. Consider, for example, fer aire 'it's windy', fer fred 'it's cold', tenir son 'to be sleepy', and tenir gana 'to be hungry'.

9. Consider, for example, expressions with pure light verbs (as in fer sol 'it's sunny', tenir morro 'to be cheeky'), expressions with heavier light verbs (as in posar botiga 'to set up shop', passar llista 'to call (the) roll'), or even expressions with non-light verbs (as in plantar cara (a algú) 'to stand up (to someone)', buscar pis 'to look for a flat', guardar lloc 'to keep a seat'). 
figuration. Taking into consideration a lexicalist approach to the nature of argument structure (Hale - Keyser 1993, 1997, 1998, 2000, 2002), lexicalized expressions which contain just one internal argument position might be represented in (1-)syntax as in (14), and lexicalized expressions which contain two internal argument positions might be represented in (l-)syntax as in (15). ${ }^{10}$

(14) a. Hale - Keyser (1997:204)

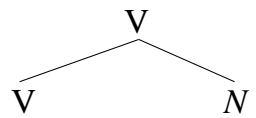

(15) a. Hale - Keyser (1997:206)

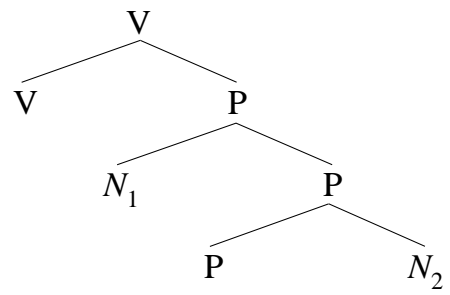

A simple $\mathrm{V}+\mathrm{N}$ complement structure in (14) contrasts with a complex dyadic complement structure in (15). As summarized by Mateu (2001:89): «the structural difference between transitive structures and unergative structures is based on the type of complement selected by the causal / source relation: While a spatial relation is selected in [15] as complement, it is a non-relational element that is selected in [14]». But, not only that, a bare noun object in (14) contrasts with a $\mathrm{D}$ (eterminer) $\mathrm{P}$ (hrase) at the external argument position of the relational prepositional head in (15); notice that a DP stands for the $\mathrm{N}_{1}$ in (15a)). Accordingly, (13a) - together with the rest of class 1 idioms - has the basic argument structure in (16):

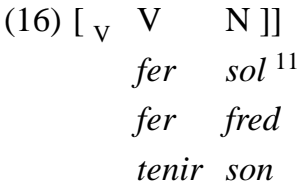

10. Some alternative linguistic models which would also make a distinction between monadic and dyadic argument structures are a minimalist syntactic approach (Uriagereka 1999), and a semantically based lexical-syntactic account (Mateu 2000, 2001, 2002).

11. Strong evidence for the monadic argument status attributed to a sequence such as fer sol (lit. make sun) 'it's sunny' comes from the idiomatic expression Plou i fa sol (lit. rain and make sun) 'Sunny showers', which coordinates two basic unergative argument structures: make rain and make sun. Notice that true constituent conjunction requires identical types (see Partee 1987:119, among many others). 
whereas (13b) —and the rest of class 2 idioms - has the basic argument structure in (17):

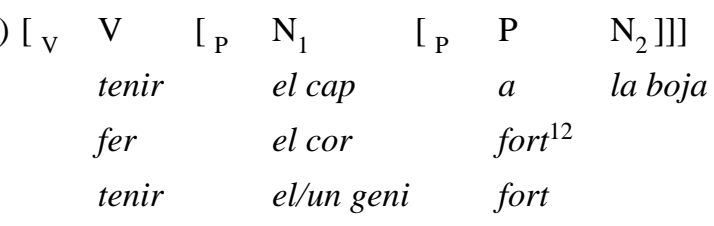

Furthermore, it should be noticed that, by postulating different basic argument structures for class 1 and class 2 idioms, it is possible to predict the different syntactic behavior described in Section 2 with regard to pronominalization. The YP constituent of class 1 idioms (that is, the apparent second complement of these expressions) cannot be pronominalized, since it is not part of its argument structure; in the next section I shall postulate that this YP is a right branch constituent which is merged to an independently generated quantified noun. By contrast, the YP constituent occurring in class 2 idioms can be pronominalized (although with some lexical restrictions), because it corresponds to the embedded spatial relationship of the dyadic argument structure underlying this paradigm.

In Section 2 I further mentioned that class 1 idioms are fixed with the $\mathrm{D}$ un ' $\mathrm{a}$ ', whereas class 2 idioms show a D alternation. For the time being, notice that the object complement of the monadic light verb argument structure lacks a D, it is always a bare $\mathrm{N}$, whereas the object complement of the dyadic argument structure has argument properties, and therefore it must be specified by either a definite or an indefinite D. In the next section a syntactic analysis of class 1 and class 2 idiomatic patterns is provided.

\section{The syntax of lexicalized light-verb structures}

So far I have dealt with the basic elements of the argument structures underlying (1) and (2).

An appropriate structural account of the relevant patterns involved in (1) and (2) is now required. Let me remind the reader that, from a conceptual point of view, pattern 1 expresses a semantic conflation, a cause plus degree synthesis, whereas pattern 2 expresses an abstract spatial relationship. ${ }^{13}$

12. See Mateu (2002) for syntactic support on the derived status of the lexical category Adjective.

13. Notice that the conflated meaning between cause and degree exists only phrasally, but not lexically; that is, there is not a synthetic verb whose meaning expresses cause and high degree as in class 1 idioms.

It should further be noted that the notion of Conflation was originally postulated as a semantic term within the cognitive semantics tradition. More specifically, Talmy's (1972, 1985, 2000) conflation has been postulated in order to refer to the various existing ways of representing meanings in surface forms: to the fact that a $\mathrm{V}$ may express at once both motion and manner, or motion and cause, or motion and path, or motion and figure, etc. 
In this section I would like to show that in (sentential-)syntax (Hale - Keyser 1993) the representation corresponding to class 1 idiomatic expressions is the output of various Merge operations between syntactic objects, whereas the representation corresponding to class 2 is a composite argument structure created by means of a syntactic conflation process under specific structural conditions. $^{14}$

Let us first consider the (lexical-)syntax of class 1 idioms. I have already advanced the hypothesis that their basic argument structure is that corresponding to a monadic configuration, as represented in (14) (repeated in (18)), since it contains just one complement (Hale - Keyser's 1998 (11a) type). Furthermore, I postulate that the nominal it contains has the formal feature [- i], which stands for negative internal structure (Jackendoff 1991). ${ }^{15}$ The presence of a noun with this formal characterization within this particular argument structure determines a property denoting reading for the noun (i.e. a continuously divisible entity).

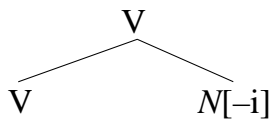

In (sentential-)syntax this basic syntactic object undergoes various Merge operations. ${ }^{16}$ First, a functional category $\mathrm{Q}$, whose terminal node is $u n$ 'a', is merged with N. Second, an X constituent (either of category P, N, that, or whatever) is adjoined-in with $\mathrm{N}$, giving as output the structure in (19).

This notion has been recently reinterpreted in syntactic terms. According to Hale - Keyser (1993, 1997, 1998, 1999) and Mateu - Rigau (2002), the term conflation is used as a concomitant of Merge, to refer to a subtype of incorporation involved in the derivation of denominal and deadjectival verbs, «restricted to the process according to which the phonological matrix of the head of a complement $\mathrm{C}$ is introduced into the empty phonological matrix of the head which selects (and is accordingly sister to) C» (H-K 1998:81).

Finally, Hale-Keyser (2000:10) reinterpret conflation as an operation on labels which consists in the process of copying phonetic features.

14. The analysis put forward in this section differs from Lebeaux's (1988) analysis of the fixedness of the determiner in idiomatic constructions, which is based on the hypothesis that idioms with a fixed definite determiner cannot passivize and are generated at a level of derivation where theta representations are merged with case representations (i.e. post-merger idioms), whereas idioms without a specified determiner allow passivization and are listed at the level of thematic representation (i.e. theta type idioms). A different analysis is supported by the fact that neither class 1 and class 2 idioms nor light verb structures of the type illustrated in (3) allow syntactic passivization.

15. According to Jackendoff (1991:20), the feature value [- i] characterizes both individuals (e.g. pig) and substances (e.g. water), whereas [+ i] is believed to define both groups (e.g. committee) and aggregates (e.g. buses, cattle)

16. According to Chomsky (1995:226) the Merge operation «takes a pair of syntactic objects $\left(\mathrm{SO}_{i}\right.$, $\mathrm{SO}_{j}$ ) and replaces them by a new combined syntactic object $\mathrm{SO}_{i, j} \gg$. 
(19)

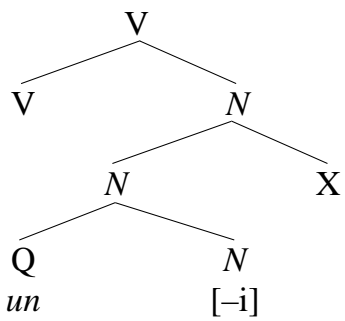

Following Lebeaux (1990) I hold the hypothesis that the phrase-marker in (19) is not generated as it is, but rather is composed out of smaller units, in the course of the derivation. Adjuncts are not base generated, since they are not required in the base (at argument structure representation), but they are merged derivationally. The two basic argument substructures involved in (19) for a class 1 idiom like fer un sol de justícia 'it's scorching hot' are isolated in (20):

(20) Basic argument structures

$\mathrm{s}_{1:} \quad[\mathrm{V}$ fer sol ]

$\mathrm{s}_{2:} \quad{ }_{\mathrm{P}}$ de justicia ]

$\mathrm{s}_{1}$ and $\mathrm{s}_{2}$ are pure representations of the argument-of relationship that holds between a light-verb predicate (either a verbal head or a prepositional head) and its internal complement. I posit that they make manifest monadic argument patterns, which should not be confused with standard thematic configurations.

The operation composing these substructures is called Adjoin-a, for it is believed that adjuncts do not form a unitary representation with the main clause in the base. Rather, they are part of a collection of substructures which are adjoined-in in the course of the derivation, as illustrated in (21).

(21) Derivation

$$
\left.\begin{array}{ll}
\mathrm{s}_{1:} & \begin{array}{l}
\left.{ }_{\mathrm{V}} \text { fer sol }\right] \\
\end{array} \\
& \left.{ }_{\mathrm{V}} \text { fer } \text { un } \text { sol }\right] \\
\mathrm{s}_{2:} & \left.{ }_{\mathrm{P}} \text { de justicia }\right]
\end{array}\right\} \text { - } \mathrm{Q} \text {-merge } \rightarrow
$$

The output structure in (21) is to be interpreted at the syntax-semantics interface as compositionally conveying an existential quantification over a particular property, the property denoted by the head noun object complement of the monadic argument structure in (18). It further determines modification by an adjunct.

If, instead of (18), the basic lexical argument structure contains just a head N, then the output of the two merging processes would look like (22). 
(22)

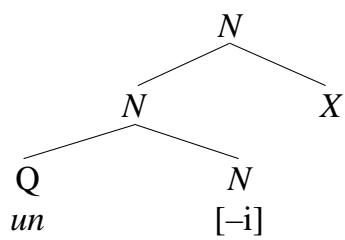

The idea is that a single Noun can also Merge with a quantifier and an additional substructure in an adjoin-in relation under agreement conditions among lexical features: [ de justícia ] can only be adjoined to [ un sol ], not to any other of the nominals listed in (3). ${ }^{17}$ This is how the lexicalized nominal expressions listed in (11) are assumed to be derived.

I now turn to the syntax of the lexicalized light verb expressions illustrated in class 2 idioms. Assuming the set of lexical argument structures postulated by Hale - Keyser (1998), the structural configuration underlying (2) looks like a composite argument structure (see (15) above) which combines a monadic V-projection (the one represented in (23)) with a dyadic prepositional structure (the one represented in (24)).

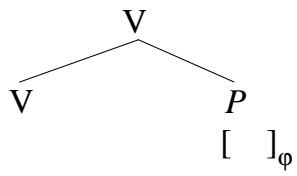

(24)

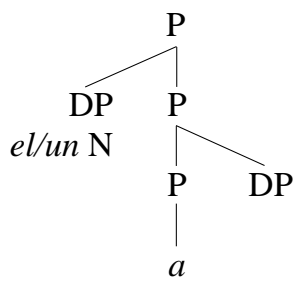

Notice that in (23) V stands for a light verb expressing cause, either dynamic cause (e.g. fer 'make', posar 'put') or an internal abstract cause (e.g. tenir 'have') (Mateu - Amadas 2001). The complement of the V is assumed to be a P(reposition) with a null phonological matrix, thus motivating the generalized transformation which substitutes (24) for the phonologically empty P in (23). ${ }^{18}$ In (24) P is to be associated with a spatial relationship semantically expressing central coin-

17. This restriction is assumed to be non-compositional, not to be drawn from the computational system, but rather from what Marantz $(1996,1997)$ recently called the 'Encyclopedia component'.

18. It is commonly assumed that it is a property of phonologically empty heads that they attract the phonological matrix of a complement $\mathrm{N}$ only when they share the formal features of the complement. 
cidence (notice that the prepositon $a$ 'at' can overtly occur as a terminal node), with both a specifier DP and a complement DP arguments. The output structure looks like (25).

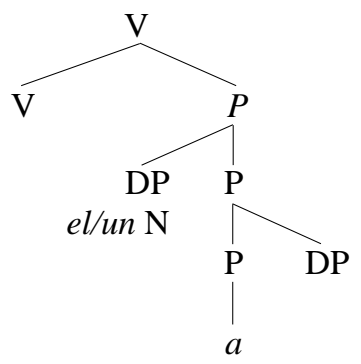

Insertion of a dyadic argument structure into a monadic argument structure gives an acceptable transitive structure as an output: the one represented in (25), which is assumed to underlie all class 2 idioms.

Let us now move on to some aspects concerning the meaning of class 1 and class 2 idioms at the syntax-semantics interface. In the next section I shall deal with:

- The basic characteristics of object noun interpretation in both monadic and dyadic argument structures.

- The basic linguistic status of the nominal specifier in both paradigms.

- The semantic composition of lexicalized degree expressions.

\section{The semantics of lexicalized light-verb structures}

Assuming a transparent syntax-semantics mapping (see Montague 1974, Chierchia 1998, Herburger 2000, among many others), I will show that nominal expressions in class 1 and class 2 idioms map into clearly distinct logical objects. ${ }^{19}$

A widely adopted proposal in the linguistic literature has been that bare arguments unambiguously refer to kinds, thus aligning the interpretation of bare plurals with that of proper names and definites (Carlson 1977a, 1977b, 1999; Chierchia 1998). In addition, Romance argument bare plurals have been claimed to be a type of indefinites (variables, existentially or generically bound; Longobardi 2001), although some arguments have also been put forward towards the hypothesis that bare plurals denote properties (McNally 1995; see also Laca 1996). ${ }^{20}$ However,

19. From the vast amount of literature on the semantics of nouns, and in particular on the semantics of bare nouns, see Carlson (1977a, 1977b, 1999), Chierchia (1998), Laca (1996), Longobardi (2001), McNally (1995), and Partee (1987).

20. A general assumption of Longobardi's recent work (Longobardi 1996, 2001), is that Romance argument bare nouns are nothing but a type of indefinites (Heim 1982), like overt indefinites and unlike proper names. By contrast, English bare nouns are said to be ambiguous between a 
not much attention has been paid to the interpretation of bare singular count nouns in argument position, in spite of the fact that they are not rare in Romance languages (see the data given in note 3 ).

Therefore, we are still in need of a semantic theory which accounts for the meaning of bare singulars. Following previous work (Espinal 2001, 2002), I would like to put forward the hypothesis that bare count / discrete singulars in object position denote properties, and that this interpretation is determined by the argument structure configuration in which they occur.

Let us assume that a canonical mapping of nominal categories into their denotations holds, that is, that DPs are arguments, while NPs (common nouns) are predicates. This idea, which reminds us of Vergnaud - Zubizarrreta's (1992:612) Correspondance Law, has been developed by Chierchia (1998:343) in the following terms: «Bare nouns, qua restrictions of quantifiers, must be predicates. (...) On the other hand, DPs, qua arguments of verbs, must be of the canonical argumental types, namely $e$ (for referential nominals) or G(eneralized) Q(uantifiers) (for quantificational nominals)». Similarly, bare count singulars occurring in object position of monadic argument structures can be interpreted as restrictions of quantifiers, but not as referential arguments. Accordingly, keeping on strict argument structural terms, when the $\mathrm{V}+\mathrm{N}$ monadic argument structure is projected into syntax, the bare $\mathrm{N}$ (either a bare mass / continuous noun, a singular count / discrete noun, or a bare plural) is allowed to project a $\mathrm{Q} .^{21}$

My claim is that, since the expectation regarding Romance languages (which have [-arg, +pred] NPs) is that an NP cannot be made into an argument without projecting D (Chierchia 1998:343,355), a qualification should be added to this generalization, since the data show that such a prediction only applies to dyadic argument structures. Therefore, I maintain that object complements of monadic argument structures are not licensed as object arguments, and do not require an empty D. In this type of argument structure a bare nominal object is licensed as a property which must be combined with the meaning of the light verb, presumably by some process of complex predicate formation. Alternatively, it projects a $\mathrm{Q}$ which quantifies over properties. That is, in order to preserve the above-mentioned canonical universal mapping, what is required is either a complex verb formation operation according to which the bare $\mathrm{N}$ is syntactically incorporated into the head $\mathrm{V}$, forming a complex predicate in syntax (at LF at the latest; see Guasti 1993, Safir 1995, Espinal $2001),{ }^{22}$ or the introduction of a quantification over properties.

quantificational interpretation of indefinites and a referential reading (i.e., directly kind denoting, in Carlson's 1977b terms), unlike overt indefinites and like proper names.

21. Notice that Chierchia $(1998: 341,343)$ seems to deny the existence of singular count common nouns in argument position, other than $\mathrm{P}+\mathrm{N}$, when he claims that «In both Germanic and Romance, bare singular arguments are totally impossible (if the noun is not a mass)», and concludes that: «If such [canonical] mapping is universal, then bare NP arguments cannot exist, as their type is not an argumental one. Each time one sees a bare NP argument, the category D must have been projected.»

22. On the notion of incorporation, see the initial work by Baker (1988), who postulates this operation in syntax in order to account for noun interpretation in native American Indian languages. 
Notice that if Romance bare count / discrete singulars were said to be interpreted unambiguously as kinds, or as indefinites, we would expect the object noun of the unergative fer sol ('it's sunny') to be equivalent, semantically speaking, to the object noun of the transitive fer un sol ('to design a sun') or fer sols ('to design (some) suns'), which is obviously not the case. Therefore, I posit that internal objects of monadic argument structures refer to properties, gradable nouns, a sort of semantic entity distinct from kinds. ${ }^{23}$

\subsection{On noun interpretation}

Several arguments can be provided to support the hypothesis that bare count / discrete singulars of monadic argument structures are property denoting objects.

First, it should be noticed that, when a basic argument structure of the sort represented in (14) (or (18)) cooccurs with an explicit indefinite expression, no scope ambiguities arise, and the overt existential quantifier is interpreted as having wide scope over the bare noun. Consider (26):

(26) a. Feia sol en unes aules, però no en unes altres.

made sun in some rooms, but not in some others

'It was sunny in some rooms, but not in others'.

b. Feia un sol de justícia en unes aules, però no en unes altres. made a sun of justice in some rooms, but not in some others 'It was scorching hot in some rooms, but not in others'.

What (26) exemplifies is that both the light verb expression fer sol 'It's sunny' in (3c) and the class 1 idiom fer un sol de justícia 'it's scorching hot' in (1c) must be interpreted as being in the scope of the existential quantifier unes aules 'some rooms', which syntactically occurs outside the $\mathrm{V}+\mathrm{N}$ argument structure: there are some $\mathrm{x}, \mathrm{x}$ being classrooms, where it was sunny or, by extension, where it was scorching hot. A reading according to which a particular sun is under consideration is impossible. However, if the object noun of the unergative fer sol ('it's sunny') in (3c) were a type of indefinite, then bare count singulars would be expected to have either wide or narrow scope with regard to the second quantifier occurring in the

Van Geenhoven (1998) postulates noun incorporation in semantic terms in order to account for the semantic properties of predicative indefinites in West Greenlandic. Espinal (2001) postulates object noun incorporation at the syntax-semantics interface in order to account for the property denoting interpretation corresponding to objects nouns in idiomatic constructions. See also Van Valin's (1999) criticism concerning adding this operation to the theory of grammar.

23. L. McNally (p.c.) has pointed out to me that a distinction should be made among two different uses of the term 'property'. The first one, which is more in accordance with McNally's (1995) work, is conceived as a function of NPs, when they contribute a specific descriptive content to the semantics of an individual, quite independently of the presence of a definite or an indefinite D. The second one, which is the one being assumed in this paper, takes a property to be the denotation of a bare Noun, because it has no extensional referent, and it only allows quantification of degrees. 
sentence. Since this is not the case, only a hypothesis according to which bare count singulars denote properties is compatible with an appropriate interpretation of the data.

A second argument supporting the claim that the object noun in (14) (or (18)) denotes a property is provided by the fact that both count and mass nouns in the expressions in (3) allow, as an alternative to the idiomatic pattern, either a degree quantifier or a degree modifier in prenominal position. Consider the paradigm in (27), especially the contrast between the ill-formed (27b) and the well-formed (27c-e). I take the well-formed combination of a quantifier / modifier expressing degree followed by a count Noun in $(27 \mathrm{c}-\mathrm{e})$ as a basic test illustrating the possibility that a measure function (Krifka 1989:81), materialized by the degree expressions força 'quite', un bon 'a good', and gaire 'much', operates on the count Noun sol 'sun'. Similarly, the quantifier and the adjunct constituents in a class 1 idiom such as fer un sol de justícia 'it's scorching hot' contribute to a measure-like function over gradable properties.

(27) a. A l'aula feia sol.

at the classroom made sun

'It was sunny in the lecture theatre'.

b. *A l'aula feia un sol. ${ }^{24}$

at the classroom was a sun

c. A l'aula feia força sol.

at the classroom made quite sun

'It was really hot in the lecture theatre'.

d. A l'aula feia un bon sol. at the classroom made a good sun

'It was bright and sunny in the lecture theatre'.

e. A l'aula no feia gaire sol.

at the classroom not made much sun 'It was not really hot in the lecture theatre'.

Third, the object nouns in (1) and (3), even in the case of singular count nouns, do not allow a plural form, thus suggesting that there is no sense in postulating a $\mathrm{D}$ position responsible for a hypothetical plural reading. If we have in mind that in Catalan kinds are usually expressed by definite NPs (whether singular or plural), the plural test can be used as an additional argument for the claim that bare nouns do not denote kinds. See the contrast in (28).

24. Notice that omission of the adjunct YP is acceptable if, and only if, specific morphosyntactic instructions remain at the phonetic-articulatory interface which specify that $u n$ ' $\mathrm{a}$ ' is not a cardinal quantifier over individuals, but rather an existential quantifier over degrees. Accordingly, (i) can only be accepted, with a suspended intonation, if $u n$ ' $a$ ' is interpreted as quantifying an extent.

(i) Fa un sol!

makes a sun 'It's so sunny!'

Fer un sol is only grammatical in the transitive sense of making, designing a sun. 
(28) a. *A l'aula feia sols.

at the classroom made suns

b. *A l'aula feia sols de justícia. at the classroom made suns of justice

Fourth, the object Nouns in (1) and (3) cannot be affected by a numeral quantifier, thus showing that they are distinct from both kinds and individuals, which —as already mentioned - are usually expressed by definite NPs (being preceded either by a D or a numeral Q).

(29) a. *Avui ha fet dos sols.

today has made two suns

b. *Avui ha fet dos sols de justícia. today has made two suns of justice

Therefore, I conclude that in monadic argument structures the complement denotes a property, a gradable noun, not a kind, an individual or a quantified individual entity (Carlson 1977a, 1977b), and, because of this, it only allows quantification and modification over degrees. Furthermore, the fact that the indefinite quantitier $u n$ ' $a$ ' in class 1 idioms cannot alternate with either a definite $\mathrm{D}$ or a zero D is in accordance with its semantic interpretation, introducing an existential quantification over degrees.

If we now turn to class 2 idioms, it should be noted that in dyadic argument structures the complement noun, denotes either a kind, an individual or a quantifier, and, as such, it only allows quantification over individual entities. This is illustrated in (30a), which contrasts with the ill-formed $(30 \mathrm{~b}, \mathrm{c})$.

(30) a. M'han posat el / un cap com un tabal.

$\mathrm{Cl}$ have put the / a head as a drum 'They drove me mad'

b. *M'han posat cap.

$\mathrm{Cl}$ have put head

c. *M'han posat força cap.

$\mathrm{Cl}$ have put quite head

Such a paradigm suggests that the semantic contribution of object nouns in class 2 idioms is that of an individual (sometimes, a kind). This assumption is supported by three additional considerations. First, some object nouns appear in the plural form (see (2c)). Second, some allow a Determiner alternation between definite $e l$ 'the' and indefinite $u n$ ' $\mathrm{a}$ ' (see $(2 \mathrm{f}, \mathrm{g})$. And, third, these object nouns are always external arguments of a secondary predication. ${ }^{25}$ 


\subsection{On the status of $\underline{u n}$ ' $a$ '}

My next task will be to identify the linguistic status of un ' $a$ ' in class 1 idioms. Notice that there is an interesting asymmetry, which is exemplified in the following paradigms.

(31) a. *fer un sol. make a sun

b. Fer sol $(=4 c)$. make sun

'It's sunny'.

(32) a. un sol de justícia. (=12b)

a sun of justice

'Scorching hot'.

b. *sol de justícia. sun of justice

(33) a. fer un sol de justícia. (=1c)

Class 1 make a sun of justice

'It's scorching hot'.

b. *fer sol de justícia. make sun of justice

We have already seen that in object position a bare noun is licensed directly by the verbal head only within monadic argument structures, as in (31b). But, when an adjunct modifier is added to the structure, as in (32a) and (33a), then the nominal requires a proper licenser, and the existential quantifier $u n$ ' $a$ ' in all the data illustrating this idiomatic pattern is the unique licenser allowed in this structure. ${ }^{26}$ Therefore, I take the data in (32) and (33) as providing strong evidence for the claim that, syntactically, the existential quantifier supports the adjunct YP, and forms a sort of discontinuous measure constituent with it. ${ }^{27}$

From a semantic point of view, un 'a' introduces, as expected, some sort of quantification. But, what does it quantify over? I posit that in class 1 idioms un introduces an existential quantification over degrees, whereas in class 2 idioms it introduces an existential quantification over individual entities.

In this section I shall consider some arguments in support of the hypothesis that $u n$ ' $\mathrm{a}$ ' in class 1 idioms is a $\mathrm{Q}$ which introduces an existential quantification over degrees, a sort of measure construction which derives a quantized predicate from a [- i ] head Noun (Krifka 1989).

com un bombo 'to be in a muddle' (lit.: have the / a head as a drum) means that there is an entity, namely a head, which is mapped into a property, namely a thought, a worry, metaphorically interpreted in the encyclopedic component as being in a muddle.

26. The ungrammaticality of (33b) shows that in this paradigm a null $\mathrm{D}$ is not licensed at all by the verbal head.

27. Although from a different linguistic tradition, Gross-Valli (1991:48) has already claimed that: «on peut alors considérer la présence de l'article un comme un pivot de soutien du modifieur». 
First, it should be noticed that, whereas in dyadic argument structures, no matter whether they are lexicalized or not, un 'a' compositionally encodes either a cardinal or an existential quantification over individual entities, in class 1 idioms it is neither the case that the head noun denotes an individual entity, nor that the quantified nominal can be interpreted as denoting a generalized quantifier over individual entities, but rather as a generalized quantifier over degrees. See the interpretation corresponding to (34) versus that corresponding to (32a) and (33a).

(34) a. posar el / un cap com un tabal. put the / a head as a drum

b. fer el / un forat a la paret. make the / a hole on the wall
Class 2

'To drive someone mad'.

Second, in class 1 idioms only the bare noun can be the antecedent of a property denoting pronoun like Catalan en, arguing against a quantification over individual entities by the quantifier $u n$ ' $a$ '.

(35) Aquest any al juny feia un sol de justícia i en va continuar fent durant this year in+the June made a sun of justice and CL continue making during tot el juliol (sol / \# sol de justícia / \# un sol / \# un sol de justícia). whole the July (sun / \# sun of justice / \# a sun / \# a sun of justice) 'It was scorching hot in June and was still hot in July'.

Accordingly, examples such as those in (35) can only mean, compositionally, that a degree of hotness exists, relevant to a given context, which is claimed to hold at a specific moment in time, and that some degree in the scale of hotness will continue to hold during a certain period of time.

Another relevant example is provided in (36), which is an attempt to coordinate two class 1 idioms forcing an existential quantification over individual entities. Notice that the output sequence is fully unacceptable.

(36) \# Ahir feia un fred que pelava i avui en fa un que glaça el pensament. yesterday made a cold that cut and today CL makes a / one that freezes the thought

Third, it is also interesting to see what happens when a class 1 idiom interacts with a universal quantifier within a single sentence. Consider the Spanish example in (37). ${ }^{28}$

(37) Un frío de mil demonios asoló todas las ciudades.

a cold of one-thousand devils destroyed all the cities

'Freezing cold weather brought each of the cities to a stand still'. 
As expected, there are two possible readings for this sentence, depending on the relative scope between the two quantifiers. Under one interpretation, a particular degree of coldness is assumed to exist, relevant to the context, and it is the case that this degree of coldness brought each of these cities to a standstill. However, a second reading is such that, for each city being considered, there is a particular high degree of coldness, not necessarily the same for each, which has brought each of the cities to a standstill. What (37) does not mean is that there is a particular cold, conceived as a referential object, to which such and such applies.

Fourth, it should be noticed that $u n$ 'a' only supports the postnominal degree modification, and in this sense $u n \ldots$ YP is a degree expression which is in complementary distribution with regard to other degree markers occurring in nonlexicalized patterns.

(38) a. Fa \{massa, molt de, tant de, més, força, bastant de, una mica de $\}$ fred. makes $\{$ too much, very, so much, more, quite, much of, a little bit of $\}$ cold 'It's \{too, really, very, more, that, so, not much $\}$ cold'

b. *Fa \{un massa, massa un $\}$ fred. makes a too much, too much a cold

c. *Fa força fred que talla. makes quite cold that cuts

d. fa un fred que talla. makes a cold that cuts

Class 1

'It's freezing cold'

To conclude, the sequence $u n+\mathrm{N}+\mathrm{YP}$ in class 1 idioms corresponds structurally to the existential quantifier, the nominal object of a monadic argument structure, and an adjunct constituent. In this structure, Q is neither syntactically optional, nor semantically expletive. On the syntactic side, it is a constituent which is merged with $\mathrm{N}$ in the course of the derivation. On the semantic side, it denotes an existential quantification over a bare scale or scalar predicate. In the paradigm under study un ' $a$ ' is not a cardinal quantifier, as tested by the fact that the noun can never combine with numerals, rather it is a function from predicate meanings to generalized quantifiers; specifically, it denotes a function from predicate meanings to generalized quantifier expressions over degrees.

This conclusion correlates with the interpretation attributed to bare Nouns in class 1 idioms (see section 5.1). The head Noun denotes a semantic entity which allows quantification over degrees; that is, being a property denoting object, it can be modified by an expression denoting degree, particularly it can be quantified by an expression denoting an existential quantification over degrees. Therefore, under the specific syntactic circumstances which have been described (the monadic argument structure in (14), or (18)), not only mass / continuous nouns, but bare count / discrete singulars as well, are logically interpreted as property denoting objects. The importance of this conclusion is that it leads us to expand the semantic classes attributed to Nouns in Romance languages in the sense that, even though it is standardly assumed in the linguistic literature that Romance bare plurals denote either 
kinds, indefinites, or properties, bare singulars in object position of monadic argument structures must denote properties, and, from this, it is predicted that they allow quantification over degrees.

\subsection{Composing the semantics of lexicalized degree expressions}

Bare nouns in object position of monadic argument structures are interpreted in situ. ${ }^{29}$

The semantics of bare nouns, like sol 'sun' and morro 'snout' in monadic argument structures, could be represented as in (39).

$$
\begin{aligned}
& \text { a. } \| \text { fer sol } \|=\text { SCALE }_{\text {SUNNY }} \\
& \text { b. } \| \text { tenir morro } \|=\text { SCALE }_{\text {CHEEKY }}
\end{aligned}
$$

Such nouns denote an ordered set of properties, a scalar predicate, the members of which only differ in gradation or strength. On the other hand, (39a) exemplifies the fer subclass, which includes those monadic expressions which do not have a high degree interpretation, and (39b) exemplifies the tenir subclass, which includes those monadic expressions that have a high degree interpretation, and are assumed to undergo a scale enrichment process (Neeleman - van de Koot - Doetjes 2003:19). On the other hand, all class 1 idioms have a high degree interpretation and, therefore, they are all assumed to undergo a scalar enrichment. This process consists on the two interpretive rules in (40), which apply in the order given.

(40) a. Scale enrichment I

$$
\mathrm{SCALE} \rightarrow U p\left(\mathrm{P}_{\text {average }}, \mathrm{SCALE}_{\mathrm{bare}}\right)
$$

b. Scale enrichment II

$\mathrm{SCALE} \rightarrow$ Distance $\left(\right.$ Considerable , $\left.\mathrm{SCALE}_{\text {derived }}\right)$

These rules are assumed to be instructions concerning the interpretation of bare scalar expressions. In particular, they account for the fact that late merge of a satellite or adjunct clause adds a(n extreme) meaning to the set of potential degrees attributed to the property expressed by the object noun, and the important point is that these rules apply independently of the lexical content of the adjunt. Thus, the semantics of (1c) and (1f) could be represented as in (41):

(41) a. $\|$ fer un sol de justicia $\left(\mathrm{P}_{\text {average }}\right)_{\mathrm{v}} \|=\exists \mathrm{P}[\mathrm{P} \in$ Distance (Considerable, $U p\left(\mathrm{P}_{\text {average }}\right.$, SCALE $\left.\left.\left._{\text {SUNNY }}\right)\right)\right]$

b. $\|$ tenir un morro que se'l trepitja $\left(\mathrm{P}_{\text {average }}\right)_{\mathrm{v}} \|=\lambda \mathrm{x} \exists \mathrm{P}[\mathrm{P} \in$ Distance (Considerable, $\left.\left.\operatorname{Up}\left(\mathrm{P}_{\text {average }}, \mathrm{SCALE}_{\text {CHEEKY }}\right)\right) \& \mathrm{P}(\mathrm{x})\right]$ 
The idea is that all class 1 idioms are evaluative degree expressions whose semantics is based on an internal ( $\mathrm{P}_{\text {average }}$ ) of admissible values, and can be described in terms of two functions $U p$ and Distance. ${ }^{30}$

In both structures the satellite (de justícia lit.: of justice, que se'l trepitja lit.: that walks on) measures the distance between the $\mathrm{P}_{\text {average }}$ and the anchor point (the high degree of sun, and the high degree of cheek). Thus, in both cases the result is that the property selected is considerably stronger than the average for the given scale. In other words, the semantics of bare nouns sometimes involves an anchor point, and this point can be made explicit by means of specific satellites.

\section{Concluding remarks}

One of the predictions inferred from this discussion is that a complete analysis of the Romance lexicalization patterns illustrated in class 1 and class 2 idioms requires (i) a syntactic argument structure representation of basic light verb structures, responsible for the different pronominalization possibilities, for the determiner distribution, and for the basic contribution to the semantics of nouns; and (ii) a logical characterization of linguistic objects, according to which nominals are properly interpreted as either kinds, indefinites or as property denoting objects.

Idioms have syntax. On the one hand, the basic elements of the argument structure of class 1 idioms correspond to a monadic argument structure, which represents the analytic type of the rather simple head-complement configuration postulated by Hale - Keyser (1998). On the other hand, the basic elements of the argument structure of class 2 idioms correspond to a composite representation, combining a monadic head-complement configuration with a dyadic specifier-head-complement structure. Furthermore, in addition to their having different basic argument types in 1-syntax (see Hale - Keyser 1993), it must be concluded that the idiomatic patterns under study are formed in sentential or s-syntax by various means: (1) an existential quantifier and an adjunct are subsequently merged to the basic monadic argument structure (see (19)), and (2) two basic argument structures: a monadic and a dyadic are combined into a composite configuration (see (25)).

This means that an appropriate mapping between syntax and semantics in the domain of the lexicalization patterns under study requires postulating various instan-

30. Paraphrasing Neeleman - van de Koot - Doetjes (2003), (41a) should be read as follows: P is an element of a set of sunny properties. A property is selected by existential closure from that scale, in such a way that the existential operator reduces the set to a single property. $\mathrm{P}_{\text {average }}$ represents the expected value for a given scale, and is used to split the ordered set introduced by the gradable noun into two subsets. Of these, the one containing stronger properties is chosen, as indicated by the functor $U p$. That is, the functor $U p$ uses $\mathrm{P}_{\text {average }}$ to split the ordered set introduced by the bare noun into two subsets, and selects the one containing stronger properties. Subsequently, the functor Distance constructs a singleton set whose member is a predicate $\mathrm{P}$ that is considerably stronger than the average for the given scale. The Encyclopaedia component is responsible for the inferential connection between the $\mathrm{SCALE}_{\text {sunny }}$ and the SCALE $\mathrm{hotness}_{\text {. }}$

In the case of (41b), the formula adds a lambda bound variable which the property selected by the existential quantifier is applied to. 
tiations of Merge. The fusion process postulated for the Romance pattern of class 1 idioms consists in adjoining a satellite to a bare $\mathrm{X}$. This operation must be distinguishable from both incorporation (in Baker's terms) and from conflation (in Hale - Keyser's terms). However, it can still be attributed to conflation in Talmy's cognitive sense. The fusion process postulated for the Romance pattern of class 2 idioms consists in inserting a dyadic argument structure into the complement position of a causative matrix verb, thus transitivizing a basic dyadic $\mathrm{P}$ projection.

The analysis put forward in this paper is also relevant for a complete semantic theory of bare nouns in Romance, and it postulates that bare count singulars are interpreted as properties, when they are in object position of a monadic argument structure. Thus, this paper contributes to a theory on the interpretation of bare nouns, by analysing the syntactic construal underlying lexicalized light verb structures. This conclusion regarding the semantics of bare singulars contrasts with Longobardi's (2001) typology on the semantics of bare nouns in object position, since according to him Romance bare nouns are basically variable like expressions (like overt indefinites and unlike proper names), either existentially or generically bound.

A further conclusion must be drawn with regard to the semantic status of un ' $a$ ' as an existential quantifier. In addition to the possibility of quantifying over individual entities, predicates, and events, I have shown that it can also quantify over gradable properties, for its semantic function is to take a predicate meaning as input and to provide a generalized quantifier over degrees as output.

The ideas presented here are theoretically interesting in at least two further respects: (1) they challenge the traditional view that lexicalized expressions are of no interest with regard to the principles of core grammar, since they are considered to be peripheral grammatical phenomena; and (2) they focus on the issue of the theoretical reductionism of lexicalized phenomena, and its relevance with regard to the learnability problem, thus challenging the traditional view that lexicalized expressions should be conceived as irregularities listed in the lexicon. I've shown the existence of two classes of idiomatic or lexicalization patterns which are completely regular as far as the compositionality of argument structure is concerned.

Finally, I would like to suggest that the view of grammar which emerges from this study is that lexicalized light verb expressions (in particular, class 1 and class 2 idioms) are generated much in line with a set of predictions made in Distributed Morphology (Halle - Marantz 1993, 1994; Harley - Noyer 1999, 2000). Lexicalized or idiomatized expressions encode information which is distributed through various components. First, within the computational component their general architecture is specified in terms of head-based licensing relationships (O'Grady 1998). The syntactic component also specifies their association with distinct basic argument structures and their submission to various types of Merge operations. Second, in the syntax-semantics interface component the logical properties of nominal expressions and determiner expressions are licensed appropriately. And, third, it is assumed that in the encyclopedia (or conceptual component) all unpredictable form and meaning relationships, i.e. all non-compositional (or figurative) associations between particular morphosyntactic constituents and specific conceptual structures, are adequately specified (Marantz 1996). 


\section{References}

Baker, Mark (1988). Incorporation. Chicago: The University of Chicago Press.

Bosque, Ignacio (2001). «On the weight of light predicates». In: Herschensohn, J.; Mallén, E. \& Zagona, Karen (eds.). Features and interfaces in Romance. Amsterdam: John Benjamins, pp. 23-38.

Bosque, Ignacio; Masullo, Pascual (1998). «On verbal quantification in Spanish». In: Fullana, Olga; Roca, Francesc (eds.). Studies on the syntax of central Romance languages. Girona: Universitat de Girona, pp. 9-63.

Carlson, Greg (1977a). «A unified analysis of the English bare plural». Linguistics \& Philosophy 1: 413-457.

Carlson, Greg (1977b). Reference to kinds in English. Amherst: University of Massachusetts, doctoral dissertation. New York: Garland, 1980.

Carlson, Greg (1999). «No lack of determination». Glot International 4.3: 3-8.

Chierchia, Gennaro (1998). «Reference to kinds across languages». Natural Language Semantics 6.4: 339-405.

Chomsky, Noam (1981). Lectures on government and binding. Dordrecht: Foris. Chomsky, Noam (1995). The minimalist program. Cambridge MA.: The MIT Press. Corver, Norbert (1991). «Evidence for DegP». In: Sherer, T. (ed.). Proceedings of the North East Linguistic Society 21: 33-47.

Espinal, M. Teresa (2001). «Property denoting objects in idiomatic constructions». In: D'Hulst, Yves; Rooryck, Johan; Schroten, Jan (eds.). Romance languages and linguistic theory 1999. Amsterdam: John Benjamins, pp. 117-142.

Espinal, M. Teresa (2002). «Idiomatic constructions vs. light verb constructions». In: Leonetti, Manuel; Fernández Soriano, Olga; Escandell, Victoria (eds.). Current issues in generative grammar. $10^{\text {th }}$ Colloquium on Generative Grammar. Selected papers. Alcalá de Henares / Madrid: Universidad de Alcalá / Universidad Nacional de Educación a Distancia / Universidad Autónoma de Madrid.

Espinal, M. Teresa (2004). Diccionari de sinònims de frases fetes. Barcelona / València: Universitat Autònoma de Barcelona. Servei de publicacions / Publicacions de l'Abadia de Montserrat / Publicacions de la Universitat de València.

Everaert, Martin; Van der Linden, Erik; Schenk, André \& Schreuder Rob (eds.) (1995.). Idioms: structural and psychological perspectives. Hillsdale: Lawrence Erlbaum Associates.

Gibbs, Raymond W. (1995). «Idiomaticity and human cognition». In: Everaert, Martin; et al. pp.97-116.

Grimshaw, Jane; Mester, Armin (1988). «Light verbs and $\theta$-marking». Linguistic Inquiry 19: 205-232.

Gross, Gaston; Valli, André (1991). «Déterminant zéro et verbes supports en moyen français et en français moderne». Langages 102: 36-51.

Guasti, M. Teresa (1993). Causative and perception verbs. A comparative study. Torino: Rosenberg \& Sellier.

Hale, Ken; Keyser, Samuel Jay (1993). «On argument structure and the lexical expression of syntactic relations». In: Hale, Ken; Keyser, Samuel Jay (eds.). The view from building 20. Cambridge MA: The MIT Press, pp. 53-109.

Hale, Ken; Keyser, Samuel Jay (1997). «The limits of argument structure». In: A. Mendikoetxea, Amaya; Uribe-Etxebarría, Myriam (eds.). Theoretical issues at the morphology-syntax interface. Bilbao: Universidad del País Vasco, pp. 203-230. 
Hale, Ken; Keyser, Samuel Jay (1998). «The basic elements of argument structure». MIT working papers in linguistics 32: 73-118. Also published in: Hale, Ken; Keyser, Samuel Jay (2002), pp. 1-27.

Hale, Ken; Keyser, Samuel Jay (1999). «A response to Fodor and Lepore, 'Impossible worlds'». Linguistic Inquiry 30.3: 453-466.

Hale, Ken; Keyser, Samuel Jay (2000). «Conflation». Cuadernos de Lingüística VII: 39-76. Madrid: Instituto Universitario Ortega y Gasset. Also published in: Hale, Ken; Keyser, Samuel Jay (2002), pp. 47-103.

Hale, Ken; Keyser, Samuel Jay (2002). Prolegomenon to a theory of argument structure. Cambridge Mass.: The MIT Press.

Halle, Morris; Marantz, Alec (1993). «Distributed morphology and the pieces of inflection». In: Hale, Ken; Keyser, Samuel Jay (eds.). The view from building 20. Cambridge MA: The MIT Press, pp. 111-176.

Halle, Morris; Marantz, Alec (1994). «Some key features of distributed morphology». In: Carnie, A. \& Harley, Heidi (eds.). MIT Working Papers in Linguistics 21: Papers on phonology and morphology. Cambridge MA: The MIT Press, pp. 275-288.

Heim, Irene (1982). The semantics of definite and indefinite NPs. Amherst: University of Massachusetts, doctoral dissertation. New York: Garland, 1989.

Harley, Heidi; Noyer, Rolf (1999). «Distributed morphology». Glot International 4.4: 3-9.

Harley, Heidi; Noyer, Rolf (2000). «Formal versus encyclopedic properties of vocabulary: Evidence from nominalizations». In: Peeters, B. (ed.). The lexicon-encyclopedia interface. Current research in the semantics / pragmatics interface. Amsterdam: Elsevier, pp. 349-374.

Herburger, Elena (2000). What counts. Focus and quantification. Cambridge MA: The MIT Press.

Higinbotham, James (1985). «On semantics». Linguistic Inquiry 16.4: 547-593.

Jackendoff, Ray (1991). «Parts and boundaries». Cognition 41: 9-45.

Jackendoff, Ray (1997). The architecture of the language faculty. Cambridge MA: The MIT Press.

Krifka, Manfred (1989). «Nominal reference, temporal constitution and quantification in event semantics». In: Bartsch, Renate; van Benthem, J.; van Emde Boas, P. (eds.). Semantics and contextual expression. Dordrecht: Foris, pp. 75-115.

Laca, Brenda (1996). «Acerca de la semántica de los plurales escuetos del español». In: Bosque, Ignacio (ed.). El sustantivo sin determinación. La ausencia de determinante en la lengua española. Madrid: Visor, pp. 241-268.

Lebeaux, David (1988). Language acquisition and the form of the grammar. Amherst: University of Massachusetts, doctoral dissertation. Amsterdam: John Benjamins, 2000.

Lebeaux, David (1990). «Relative clauses, licensing, and the nature of the derivation». NELS 20.2: 318-332.

Levin, Beth; Rappaport Hovav, Malka (1995). Unaccusatives: At the syntax-lexical semantics interface. Cambridge, Mass.: The MIT Press.

Longobardi, Giuseppe (1996). «The syntax of N-raising: a minimalist theory». Utrecht Institute of Linguistics OTS. Utrecht.

Longobardi, Giuseppe (2001). «How comparative is semantics. A unified parametric theory of bare nouns and proper names». Natural Language Semantics 9.4: 335-369. 
Marantz, Alec (1996). «Cat as a phrasal idiom: Consequences of late insertion in Distributed Morphology». Cambridge MA: MIT, ms.

Marantz, Alec (1997). «No escape from syntax: Don't try morphological analysis in the privacy of your own lexicon». In: Dimitriadis, Alexis; Siegel, Laura; SurekClark, Clarissa; Williams, Alexander (eds.). University of Pennsylvania working papers in linguistics 4:2: Proceedings of the 21 ${ }^{\text {st }}$ Annual Penn Linguistics Colloquium. Philadelphia: University of Pennsylvania, pp. 201-225.

Mateu, Jaume (2000). «La semàntica relacional de l'estructura argumental i la seva aplicació a una alternança lexicosemàntica del català». Llengua \& Literatura 11: 281-309.

Mateu, Jaume (2001). «Unselected objects». In: Dehé, N.; Wanner, A. (eds.). Structural aspects of semantically complex verbs. Berlin: Peter Verlag, pp. 83-104.

Mateu, Jaume (2002). Argument structure. Relational construal at the syntax-semantics interface. Bellaterra: Universitat Autònoma de Barcelona, doctoral dissertation.

Mateu, Jaume; Amadas, Laia (2001). «Syntactic Tools for Semantic Construal», research report GGT-01-12. Bellaterra: Universitat Autònoma de Barcelona. http://seneca. uab.es/ggt/reports.htm

Mateu, Jaume; Espinal, M. Teresa (forthcoming). «Argument structure and compositionality in idiomatic structures». Bellaterra: Universitat Autònoma de Barcelona, ms.

Mateu, Jaume; Rigau, Gemma (2002). «A minimalist account of conflation processes: parametric variation in the lexicon-syntax interface». In: Alexiadou, Alexandra (ed.). Theoretical approaches to universals. Amsterdam: John Benjamins, pp. 211-236.

McGinnis, Martha (2002). «On the systematic aspect of idioms». Linguistic Inquiry 33.4: 665-672.

McNally, Louise (1995). «Bare plurals in Spanish are interpreted as properties». In: Morrill, Glyn \& Oehrle, R. (eds.). Formal grammar. Barcelona: Universitat Politècnica de Catalunya, pp. 197-222.

Mendívil, José Luis (1999). «Las palabras disgregadas. Sintaxis de las expresiones idiomáticas y los predicados complejos». Zaragoza: Prensas Universitarias de Zaragoza.

Montague, Richard (1974). Formal philosophy: selected papers of Richard Montague. In: R.H. Thomason (ed.). New Haven: Yale University Press.

Neeleman, Ad; van de Koot, Hans; Doetjes, Jenny (2003). «Degree expressions». London \& Utrecht: University College London \& Utrecht Institute of Linguistics OTS, ms.

Nunberg, Geoffrey; Sag, Ivan; Wasow, Thomas (1994). «Idioms». Language 70.3: 491-538.

O'Grady, William (1998). «The syntax of idioms». Natural Language and Linguistic Theory 16: 279-312.

Ojeda, Almerindo (1984). «A note on the Spanish neuter». Linguistic Inquiry 15: 171-173.

Partee, Barbara (1987). «Noun Phrase interpretation and type-shifting principles». In: Groenendijk, Jeroen; et al. (eds.). Studies in discourse representation theory and the theory of generalized quantifiers. Dordrecht: Foris, pp. 115-143.

Safir, Ken (1995). «Abstract incorportion vs. abstract cliticization». Chicago Linguistics Society 31: 280-299. 
Simatos, Isabelle (1997). «Expression idiomatique, expression figée, prédicat complexe». In: Fradin, Bernard; Marandin, Jean-Marie (eds.). Mot et grammaires. Paris: Didier, pp. 89-127.

Stowell, Tim (1983). «Subjects across categories». The Linguistic Review 2: 285-312. Talmy, Leonard (1972). Semantic structures in English and Atsugewi. Berkeley, University of California at Berkeley, doctoral dissertation.

Talmy, Leonard (1985). «Lexicalization patterns: semantic structures in lexical forms». In: Shopen, Tim (ed.). Language typology and syntactic description. III: Grammatical categories and the lexicon. Cambridge: Cambridge University Press, pp. 57-149.

Talmy, Leonard (2000). «Lexicalization patterns». In: Toward a cognitive semantics. II: Typology and process in concept structuring. Cambridge MA: The MIT Press, pp. 21-146.

Uriagereka, Juan (1999). Rhyme and reason. An introduction to minimalist syntax. Cambridge MA: The MIT Press.

Van Geenhoven, Veerle (1998). Semantic incorporation and indefinite descriptions. Stanford: Center for the Study of Language and Information.

Van Valin, Robert Jr. (1999). «Incorporation in Universal Grammar: a case study in theoretical reductionism». Journal of Linguistics 28:199-220.

Vergnaud, Jean Roger; Zubizarreta, María Luisa (1992). «The definite determiner and the inalienable constructions in French and in English». Linguistic Inquiry 23.4: 595-652. 